\title{
Emotionality and conditioned avoidance responding in the squirrel monkey following septal injury'
}

\author{
ROGER W. BUDDINGTOH, FREOERICK A. KING AND LAMAR ROBERTS \\ DIVISION OF NEUROSURGERY AND CENTER FOR NEUROBIOLOGICAL SCIENCES, UNIVERSITY OF FLORIDA
}

There were no observable postoperative increases in emotional reactivity of squirrel monkeys sustaining bilateral lesions of the septal area. Septal lesions, however, signicantly enhanced the acquisition of two-way conditioned shock-avoidance responding (CAR) to a performance criterion of eight avoidances in a block of 10 consecutive trials.

Increments in emotional reactivity and in active conditioned shock-avoidance responding (CAR) in a two-way shuttle box have consistently appeared following damage to the septal area of the rat (King, 1958; Krieckhaus et al, 1964; Kenyon \& Krieckhaus, 1965). An increment in two-way CAR performance following septal injury has also been observed in the hamster (Matalka, 1964) and in the cat (McCleary, 1961; Fox et al, 1964). However, no postoperative increment in the emotional reactivity of the hamster was observed by Sodetz et al (1967), and Bond et al (1957) reported a conspicuous absence of "rage reactions" in a large number of cats with lesions in the septum, fornix, and anterior thalamus. Moore (1964), however, described the appearance of irritability in cats after some, but not all, septal lesions. Furthermore, when present, the appearance of irritability in the cat lacked the intensity of the full blown septal syndrome of hyperemotionality seen in the rat.

It appears that there are no studies directly concerned with the effects of septal ablation on the emotionality and two-way CAR acquisition of the monkey. The present study extends the data concerning these behavioral effects of septal damage to the level of the monkey. The literature indicates that in those species tinus far investigated hyperemotionality, unlike CAR enhancement, occurs reliably only in the rat following septal damage. It was therefore hypothesized that septal injury in the monkey would not result in altered emotional reactivity, but would facilitate twoway CAR acquisition. The motor activity of normal and postoperative septal animals was also evaluated. Method

Nine adult male squirrel monkeys (Samiri sciureus) served as Ss. Five monkeys comprised the normal control group, and four animals received lesions of the septal region. The apparatus was a shuttle box consisting of two $2 \times 2 \times 2 \mathrm{ft}$ compartments connected by a narrow, 7 in. long Plexiglas tunnel. To facilitate observation the front and one side of each compartment was Plexiglas. A current of $118 \mathrm{~V}$ (r.m.s.) could be delivered to the grid floors of the compartments and tunnel through a resistance of $270,000 \mathrm{ohms}$ and a scrambler (approximately $0.5 \mathrm{~mA}$ foot shock). Steady illumination was provided by a 100-W light bulb centrally located in the ceiling of each compartment. Two Hunter Model 111-B timers enabled these two ceiling lights to be flashed independently or simultaneously at the rate of 52 flashes per min.

All surgery was performed aseptically under the general anesthetic sodium pentobarbital. Electrolytic lesions were created in the septal area utilizing the coordinates derived from Gergen \& MacLean (1962).

Within two days after operation each septal animal was compared with a normal unoperated animal in his reaction to the following situations: (a) a sudden rap on the home cage stand; (b) the E looking suddenly at the monkey and throwing up a hand in the direction of the animal's cage; (c) staring directly at the animal from very near his cage for approximately 30 sec; (d) presentation of a small metal rod $4 \mathrm{ft}$ in length-this included chasing and lightly touching the animal with the tip of the rod within his cage; (e) presentation of a rubber hose-this test was identical to test (d) except that a $4 \mathrm{ft}$ section of garden hose replaced the metal rod; (f) visual presentation of a bunsen burner lighter-this consisted in igniting the lighter several times in the sight of the animal; (g) jangling of keys for approximately $60 \mathrm{sec}$. The behavior of the operated animals in each of these seven situations was recorded by protocol and, when differing noticeably from normals, briefly described. On the fourteenth postoperative day the above series of tests was repeated, and approximately $1 / 2 \mathrm{~h}$ after their completion, testing in the shuttle box was begun.

Upon being placed in the shuttle box for the first time, each animal was allowed a $5 \mathrm{~min}$ adaptation period, during which time the tunnel doors remained closed. Immediately following the adaptation period the spontaneous crosses of each animal were recorded for a $5 \mathrm{~min}$ period. The tunnel doors were lowered and raised every $60 \mathrm{sec}$ during this period. CAR training was then begun. Each CAR acquisition trial began when the tunnel doors were raised and the celling light of the cubicle in which the animal was located began flashing. These events constituted a complex CS which continued until the animal crossed to the opposite cubicle. If the animal did not cross within $5 \mathrm{sec}$ the grid floor of his compartment was electrified until he escaped. When the animal had crossed, the door was lowered and the flashing light again became steady. 


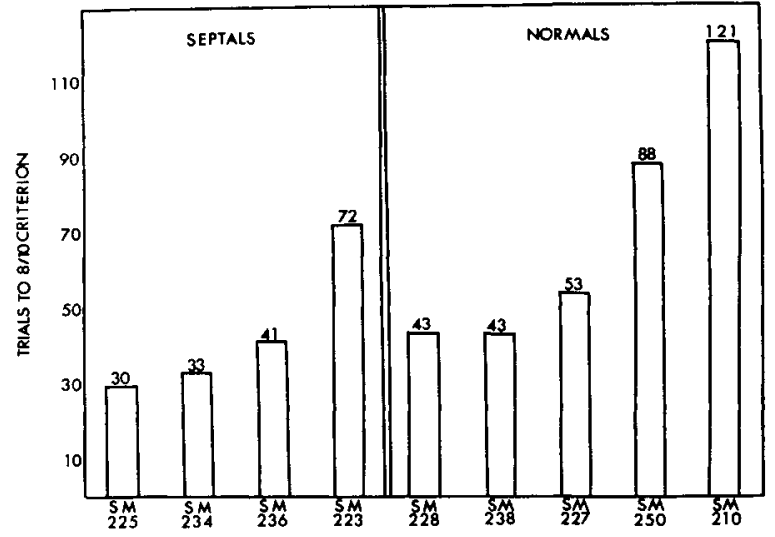

Fig. 1. Number of trials to the performance criterion of eight avoidances in a block of 10 consecutive trials. Numbers at the top of each bar indicate total trials to criterion for each animal.

Each animal was given 20 trials during his first session in the box and 40 trials each day thereafter until he reached criterion.

Results

Histology. The lesions were verified histologically and are described according to the terminology of Gergen \& MacLean (1962). Pars lateralis area septalis was damaged in all four operated animals. Damage to this structure ranged from light to heavy. Pars medialis area septalis was damaged in two (SMs 234 and 223) of the four animals. Nucleus accumbens septi was damaged in three animals (SMs 223, 225, and 236). Fasiculus olfactorius (Zuckerkandl) and fasiculus olfactorius fornicis (fornix longus) was damaged in SM 234. Gyrus rectus was damaged in all animals with the exception of SM 223. The rostrum of the corpus callosum was damaged in all animals but SM 225. SM 234 sustained the largest lesion while SM 236 had the smallest. In general the lesions tended to be small and located in the anterior portion of the septal area. ${ }^{2}$

Emotionality. There were no readily observable changes in the emotional reactions of the septal animals when they were compared with normals either two or 14 days postoperatively. On all individual tests the grossly observable behavior of the septals fell well within the range of reactions manifested by normal controls in the same situation.

Activity. Septals and normals also did not differ in the number of spontaneous crossings prior to CAR training (Mann-Whitney $U=5.5, p=.412$ two tailed). Of the septals, SMs 223, 234, and 236 made no spontaneous crossings while SM 225 made nine crosses. Four of the normals made spontaneous crosses (range two to
12 crosses) while the fifth normal, SM 210, made none.

Avoidance Learning. Septal damage in the squirrel monkey significantly enhanced (Mann-Whitney $U=3$, $\mathrm{p}=.056$ one tailed) two-way CAR acquisition to a performance criterion of eight avoidances in a block of 10 consecutive trials (see Fig. 1).

Discussion

These results are interpreted as supporting the notion, previously suggested by Sodetz et al (1967), that an increment in emotional reactivity is a species specific effect which, in the several species investigated to date, is seen reliably only in the rat following septal damage. Indeed, the observation that an increment in two-way CAR performance is observed in the septal rat even after dissipation of the hyperemotionality syndrome (Krieckhaus et al, 1964) indicates that these two effects of septal lesions are dissociable even in the rat.

\section{References}

Bond, D. D., Clark, T. R., Bidder, T. G., \& Rowland, V. Posterior septal, fornical, and anterior thalamic lesions in the cat. Arch. neurol. Psychiat., 1957, 78, 143-162.

Fox, S. S., Kimble, D. P., \& Lickey, M. E. Comparison of caudate nucleus and septal-area lesions on two types of avoidance behavior. J. comp. physiol. Psychol., 1964, 58, 380-386.

Gergen, J. A., \& MacLean, P. D. A stereotaxic atlas of the squirrel monkey's brain (Samiri sciureus). Maryland: U. S. Department of Health, Education, and Welfare, 1962.

Kenyon, J., \& Krieckhaus, E. E. Enhanced avoidance behavior following septal lesions in the rat as a function of lesion size and spontaneous activity. J. comp. physiol. Psychol., 1965, $59,466-468$.

King, F. A. Effects of septal and amygdaloid lesions on emotional behavior and conditioned avoidance responses in the rat. $J$. nerv. ment. Dis., 1958, 126, 57-63.

Krieckhaus, E. E., Simmons, H. J., Thomas, G. J., \& Kenyon, J. Septal lesions enhance shock avoidance behavior in the rat. Exp. Neurol., 1964, 9, 107-113.

Matalka, E. S. Septal forebrain lesions, emotionality and avoidance behavior in the hamster. Unpublished Master's thesis, University of Florida, 1964.

McCleary, R. A. Response specificity in the behavioral effects of limbic system lesions in the cat. J. comp. physiol. Psychol., $1961,54,605-613$.

Moore, R. Y. Effects of some thinencephalic lesions on retention of conditioned avoidance behavior in cats. J. comp. physiol. Psychol., 1964, 57, 65-71.

Sodetz, F. J., Matalka, E. S., \& Bunnell, B. N. Septal ablation and affective behavior in the golden hamster. Psychon. Sci., 1967, $7,189-190$

\section{Notes}

1. This research was supported by grant NB-02131 from the National Institute of Neurological Diseases and Blindness, and Primate Basic Support Grant HE-06379 from the National Heart Institute. 2. Copies of the lesion reconstructions may be obtained from $R$. W. Buddington. 